DOI: $10.36910 / 6775-2524-0560-2019-37-15$

УДК: 004.421:532.64

Приходько О. С. к.т.н., Приходько Г. В.

Луцький національний технічний університет

\title{
РОЗРОБКА ПРОГРАМНОГО ЗАБЕЗПЕЧЕННЯ ДЛЯ АВТОМАТИЗОВАНОГО ВИЗНАЧЕННЯ КРАЙОВИХ КУТІВ ЗМОЧУВАННЯ
}

\begin{abstract}
Приходько О. С., Приходько Г. В. Розробка програмного забезпечення для автоматизованого визначення крайових кутів змочування. Досліджено питання автоматизації обробки цифрових графічних даних експериментів по високотемпературному змочуванню. Розроблено простий та ефективний алгоритм оцифровки профілю лежачої краплі та визначення крайового кута змочування. Отримане програмне забезпечення використано для обробки результатів експериментів.
\end{abstract}

Ключові слова: змочування, крайові кути змочування, інтерполяція Лагранжа

Приходько О. С., Приходько Г. В. Разработка программного обеспечения для автоматизированного определения краевых углов смачивания. Исследован вопрос автоматизации обработки цифровых графических данных экспериментов высокотемпературного смачивания. Разработан простой и эффективный алгоритм оцифровки профиля лежащей капли та определения краевого угла смачивания. Полученное программное обеспечение использовано для обработки результатов экспериментов.

Ключевые слова: смачивание, краевые углы смачивания, интерполяция Лагранжа

Prykhodko O. S., Prykhodko H. V. Development of software for automatic determination of wetting angles. The issue of automation of processing digital graphic data of high-temperature wetting experiments is investigated. A simple and effective algorithm has been developed for digitizing the profile of a sessile drop and for determining the wetting angle. The resulting software was used to process the results of experiments.

Keywords: wetting, wetting angles, Lagrange interpolation

Постановка проблеми. Дослідження кінетики та параметрів змочування відіграють важливу роль при створені нових матеріалів з новими властивостями. Зокрема, для 3D друку за допомогою SLM (selective laser melting) технології необхідно, щоб матеріал мав хороші ливарні властивості, малу усадку та однорідну ізотропну структуру при застиганні. У статтях [1,2] показано, що додання порошку дибориду титану в алюмінієво-кремнієвий сплав усуває проблему локальних неоднорідностей (наслідок застосування SLM технології) і робить структуру надрукованого виробу більш однорідною. У цьому випадку, змочування, а отже і адгезія, безпосередньо впливає на міцність отриманого матеріалу, а отже дослідження кінетики змочування є досить актуальним. Враховуючи, що під час експериментів по змочуванню отримуються значна кількість графічних даних (іноді до десятків тисяч файлів) постає необхідність автоматизації їх обробки.

Аналіз досліджень. На даний час існує досить багато обладнання для автоматизованого визначення кутів змочування [3]. Переважна більшість подібного устаткування працює на методі ADSA (Axisymmetric Drop Shape Analysis) [12,13], який дозволяє по формі краплі визначати властивості рідин та розплавів. Суть методу полягає в виділенні контуру краплі та підборі коефіцієнтів рівняння Юнга-Лапласа, яке описує форму краплі так, щоб реальний контур співпадав 3 розрахованим.

Також варто відмітити результати отримані у роботах [9-11]. У [9] автором розроблено методику розрахунку поверхневого натягу лежачої краплі та проведено на основі неї ряд розрахунків. Однак не розглянуто питання автоматизації обробки великих об'ємів даних. В роботі [10] вдосконалено методику визначення крайового кута змочування за уточненою формулою для його розрахунку. В [11] побудовано та перевірено алгоритми розв'язання рівняння Лапласа-Юнга для різних випадків початкових даних та геометричних параметрів краплі.

Необхідність обробки великих масивів графічних даних експерименту приводить до значних витрат часу при ручному, чи навіть напівручному визначенні кутів змочування та інших параметрів. На даний час створено кілька програм, які дозволяють автоматизувати дані операції $[4,5]$. Програма, створена авторами за методикою [4] працює лише зі знімками 640x480, що суттєво спотворює результати, отримані за допомогою камер більш високої роздільної здатності. Методика [5] є досить цікавою, так як дозволяє автоматично з заздалегідь заданою точністю визначити параметри змочування, використовуючи лише максимальний діаметр лежачої краплі та ії висоту, проте неефективно працює при кутах змочування менших за $90^{\circ}$, і крім того, більш орієнтована на визначення поверхневого натягу. 
Виклад основного матеріалу та обгрунтування отриманих результатів дослідження. Для експериментального визначення параметрів змочування використовується метод лежачої краплі. На рис. 1 показано схему експерименту. На пластинку 3 досліджуваного на змочуваність матеріалу (дибориду титан, наприклад) методом СН (Contact Heating [7]) або СР (Capillary Purification [8]) наносять краплю розплавленого металу (наприклад, алюмінієво-кремнієвий сплав). Температуру, а також атмосферний склад у випробувальній камері можна змінювати. Під час експерименту проводить відеозйомка профілю лежачої краплі у контровому світлі.

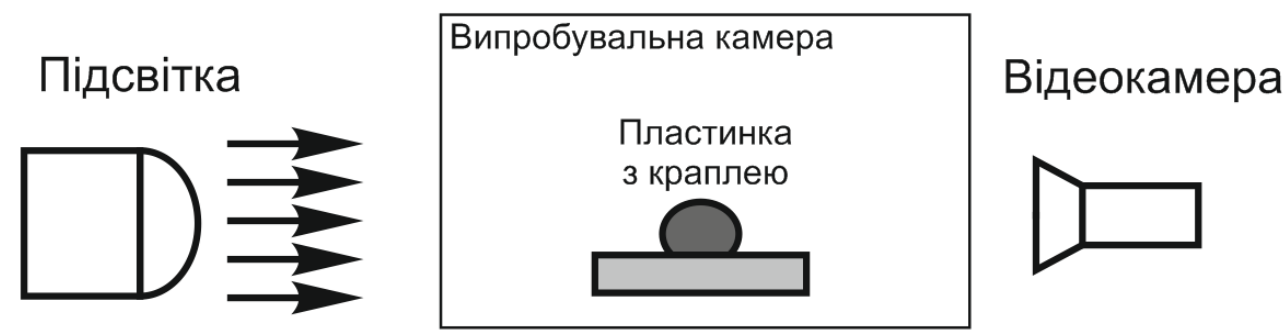

Рис. 1. Схема експериментального визначення кінетики змочування

Це досить поширена методика, яку просто реалізувати. В результаті отримується серія знімків 3 чітким обрисом краплі. На рисунку показано приклад типових кадрів на протязі одного експерименту (краплі з хорошим змочуванням.)

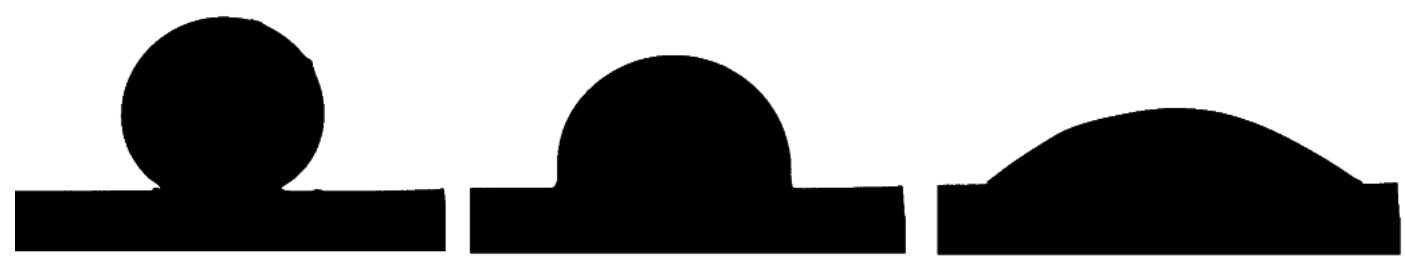

Рис. 2. Типові обриси краплі із хорошим змочуванням на протязі експерименту

Крайовий кут змочування визначається за кутом нахилу дотичної до контуру, який описує обрис краплі (рис. 3).
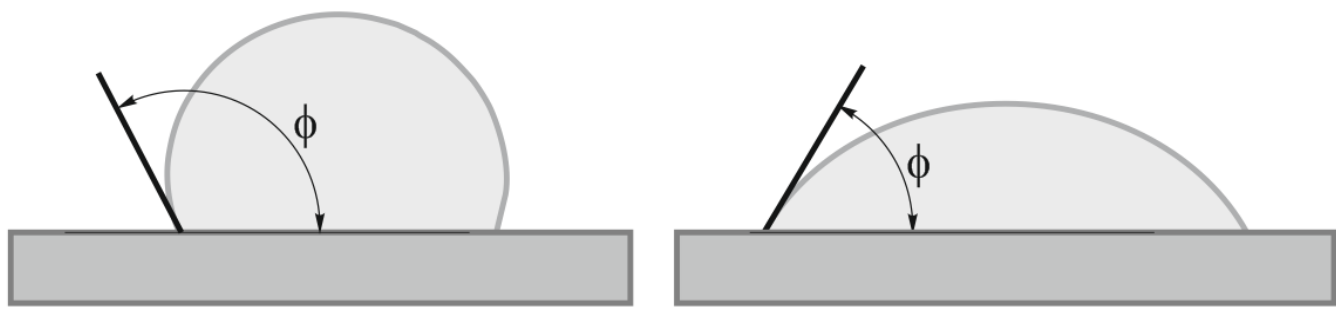

Рис. 3. Методика вимірювання крайового кута змочування лежачої краплі

Роздільна здатність знімків може бути до 4К. Проте для того, щоб відслідкувати швидкі зміни контуру краплі під час процесу плавлення та змочування (а при методі СР ще і коливання контуру після посадки краплі на пластинку) необхідно використовувати великі частоти кадрів (FPS, frame per second), що призводить до зменшення роздільної здатності (до 800х600). При FPS 10...1000 кадрів/сек отримуються тисячі (а іноді і десятки тисяч) кадрів, для кожного з яких бажано визначити кут змочування, а також інші параметри. Після визначення можна будувати графіки залежностей кута змочування, діаметру краплі, густини тощо від часу, температури.

Під час відеозйомки внаслідок недосконалого освітлення спостерігаються спотворення контуру краплі (рис. 4). 


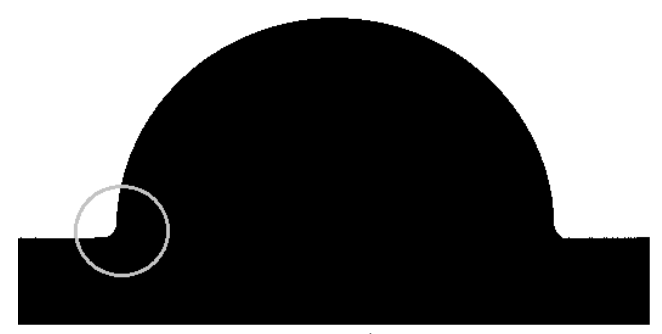

a)

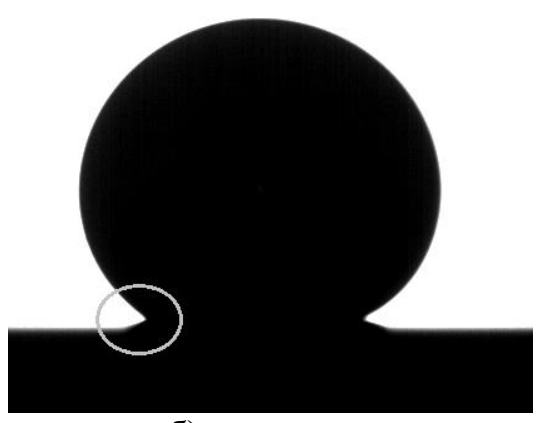

б)

Рис. 4. Приклади дефектів контуру контурів обрису лежачої краплі під час експерименту змочування, а) кут змочування $\sim 90^{\circ}$, б) кут змочування $\sim 150^{\circ}$

Знімки отримано на експериментальній установці [6] центру високотемпературних досліджень інституту ливарництва, м. Краків, Польща. Можна спостерігати спотворення форми краплі (показано колом 3 лівої сторони краплі) тінню від самої краплі. Через це втрачається інформація про крайовий кут змочування краплі біля поверхні пластинки. При кутах змочування більших $100^{0}-110^{0}$ це призводить до значних похибок (до 25-30\%). Ця проблема повністю усувається алгоритмами програми.

Методика обробки.

1. В першому наближенні кожен знімок бінаризується і представляється у вигляді двовимірного масиву RawArray, в якому 0 означає білий колір (пустота), 1 - чорний (матеріал краплі, або пластинки). Бінаризація відбувається у графічному редакторі IrfanView у пакетному режимі. Ця операція загрублює контур краплі, що призводить до несуттєвої втрати точності. В подальшому планується реалізувати в програмі обробку зображень 3256 градаціями сірого, щоб повністю уникнути втрати точності.

2. Далі необхідно визначити лінію підложки (пластинки ТіВ2). Для цього в циклі перебираються елементи масиву по координаті Y (починаючи від нуля) в діапазоні координат $\mathrm{X}_{1} \ldots$ $\mathrm{X}_{2}$ (точки 1 і 2 на рисунку 5).

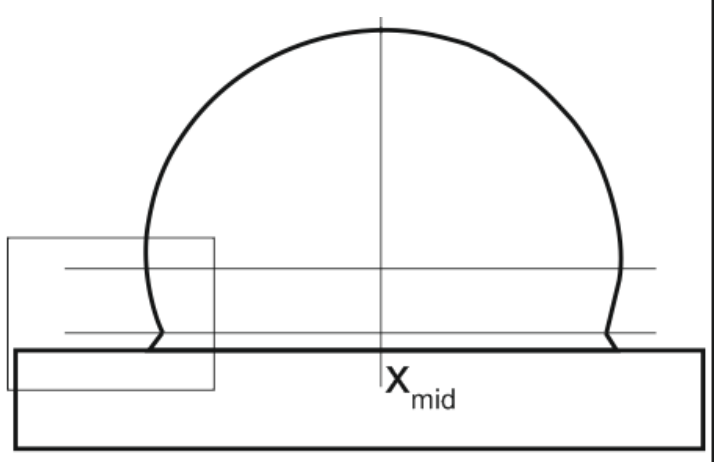

a)

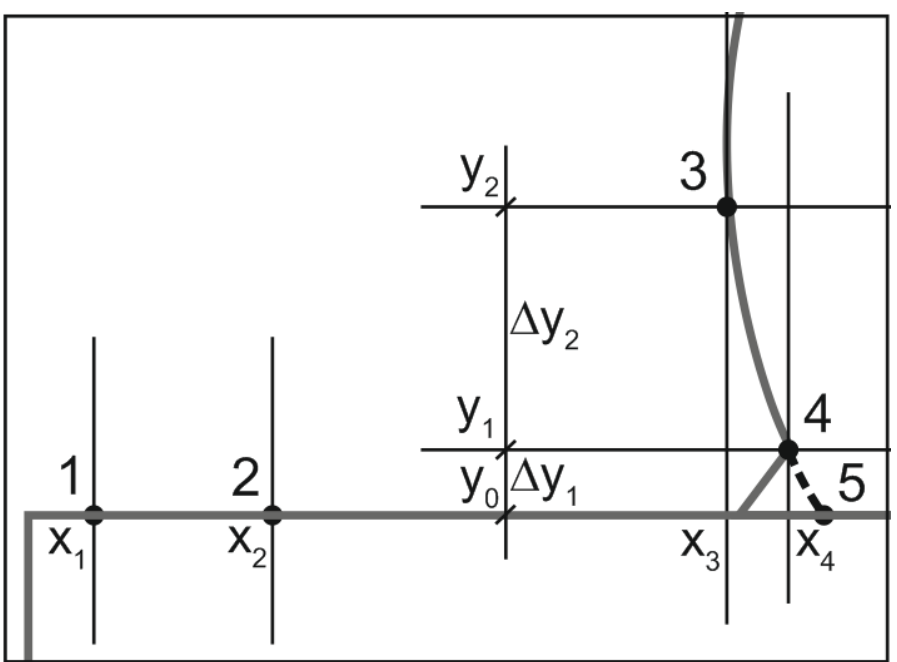

б)

Рис. 5. Схема автоматизованої обробки контуру краплі. а) - загальний вигляд, прямокутником 3 лівого боку показано межі рисунку б)

При зміні значень елементів масиву 30 на 1, їх координати У запам'ятовується i усереднюються. В результаті отримується координата $y_{0}$ (лінія підложки). Для того, щоб виключити область, спотворену тінню від краплі до $y_{0}$ додається $\Delta y_{1}$, в результаті отримується горизонтальна лінія з координатою $y_{1} . \Delta y_{1}$ задається в інтерфейсі програми окремо для кожної серії знімків. Також задається $\Delta y_{2}$, 3 таким розрахунком, щоб лінія з $y_{2}=y_{1}+\Delta y_{2}$ гарантовано проходила через краплю в кінці експерименту (коли крапля розпливається, i, відповідно, стає нижчою). В більшості випадків це 
30-60\% від початкової висоти краплі, що складає 40-50 пікселів (в залежності від кінцевої змочуванності). В результаті отримуємо на контурі краплі дві точки 3 і 4 (див. рис. 5).

3. Визначається координата $\mathrm{X}_{\text {mid }}$ центру краплі по осі $\mathrm{X}$, як середнє арифметичне всіх координат $\mathrm{X}$ ненульових елементів масиву RawArray в діапазоні $y_{1} \ldots y_{2}$.

4. Для виділення лінії контура краплі масив RawArray сканується по координаті X (X змінюється від $\mathrm{X}_{\mathrm{mid}}$ до 0) в діапазоні $y_{1} \ldots y_{2}$. При зміні значення елементу массиву RawArray 31 на 0 координати цього елементу запам'ятовувались в масив LineArray.

5. Отримані координати (елементи масиву LineArray) проходили через інтерполятор Лагранжа по 4 точкам, в результаті чого отримувався поліном 4 степеня.

$$
L=\sum_{i=0}^{3}\left(x_{i} \prod_{j=0, j \neq i}^{3} \frac{\left(y-f_{j}\right)}{\left(f_{i}-f_{j}\right)}\right),
$$

де у - змінна по осі ОУ, $f_{0}=y_{1}, f_{1}=0.33 y_{2}, f_{2}=0.67 y_{2}, f_{3}=y_{2}$

При підстановці в цей поліном значень $y_{0} \ldots y_{1}$ відновлювали спотворену тінню форму краплі (на рис. 56 показано пунктиром від точки 4 до точки 5).

6. Крайовий кут змочування визначався як акртангенс похідної від полінома в точці 5.

де

$$
\alpha=\operatorname{arctg}\left(L^{\prime}\left(y_{0}\right)\right)
$$

$$
L^{\prime}(y)=\sum_{i=0}^{3}\left(x_{i} \frac{\sum_{k=0, k \neq i}^{3} \prod_{j=0, j \neq i, j \neq k}^{3}\left(y-f_{j}\right)}{\left(f_{i}-f_{j}\right)}\right) .
$$

7. Пункти 4-6 повторювались і для правої половини краплі, лише X в пункті 4 змінювалася від $\mathrm{X}_{\text {mid }}$ до $\mathrm{X}_{\text {max }}$

В деяких випадках спостерігались осциляції даних, коли незначна зміна контуру призводила до раптової зміни кута змочування на 3-5 градусів. Це спостерігалось для контурів 3 кутами змочування близькими до $90^{\circ}$. В такому разі дані проходили через лінійну фільтрацію.

В таблиці 1 наведено порівняння фрагментів реального контуру краплі 3 графічним відображенням отриманого полінома для різних стадій експерименту. Пунктирною лінією показано фрагменти реального контуру, суцільною - результат роботи програми.

Таблиця 1. Порівняння результатів інтерполяції з фрагментами контурів краплі

\begin{tabular}{|c|c|c|}
\hline $\begin{array}{c}\text { Лівий } \\
\text { фрагмент } \\
\text { контуру }\end{array}$ & $\begin{array}{c}\text { Правий } \\
\text { фрагмент } \\
\text { контуру }\end{array}$ & $\begin{array}{c}\text { Крайовий кут } \\
\text { змочування }\end{array}$ \\
\hline
\end{tabular}

(C) Приходько О.С., Приходько Г.В. 


\begin{tabular}{|l|l|l|}
\hline $1 / 1$ & $\alpha \approx$ & $\alpha 1^{\circ}$ \\
\hline &
\end{tabular}

3 таблиці можна бачити добре співпадіння фрагментів реальних контурів краплі 3 інтерпольованими даними, а також адекватність відновлення спотвореного контуру краплі.

Висновки та практичне застосування. Алгоритми, що лежать в основі програми дозволяють автоматично та 3 достатньо високою швидкістю оброблювати дані, отримані під час високотемпературних експериментів по змочуванню. Програма була використана для обробки результатів експериментів. Обробка масиву даних $3 . .6$ тисяч знімків займає близько 20-30хв. Планується подальша модернізація програми, яка буде стосуватись визначення інших параметрів краплі (розмірів, густини, коефіцієнту поверхневого натягу тощо).

\section{References.}

1. Xi, Lixia \& Wang, Pei \& K G, Prashanth \& Li, Haichao \& Prykhodko, H.V. \& Scudino, Sergio. (2019). Effect of TiB2 particles on microstructure and crystallographic texture of Al-12Si fabricated by selective laser melting. Journal of Alloys and Compounds. 786. 10.1016/j.jallcom.2019.01.327.

2. Greer, A.. (2016). Overview: Application of heterogeneous nucleation in grain-refining of metals. The Journal of Chemical Physics. 145. 211704. 10.1063/1.4968846.

3. Drop shape analyzers [Electronic resource] : [List of laboratory equipment]. - Hamburg: KRÜSS GmbH, 2013-2015. Access mode: https://www.kruss-scientific.com/products/high-temperature/drop-shape-analyzer-dsa-high-temperature/ (Revision Date 11.12.2019) - The title from the screen.

4. L. Liggieri \& A. Passerone (1989) An automatic technique for measuring the surface tension of liquid metals, High Temperature Technology, 7:2, 82-86, DOI: 10.1080/02619180.1989.11753417

5. Levitskaya T.A. Development of a software package for processing a digital image of a sessile drop in studies of the surface properties of melts / T.A. Levitskaya // Information processing systems. - 2015. - №10. - C. 219-221

6.Instrumentation of Centre for high temperature studies [Electronic resource]: [List of laboratory equipment], Foundry Research Institute - https://iod.krakow.pl/wp-content/uploads/2018/10/katalog__EN.pdf Page 38. (date of appeal 11.12.2019) - The title from the screen.

7. Wettability and Reactivity of liquid Gd in contact with $\mathrm{Al} 2 \mathrm{O} 3$ Ceramics [Electronic resource]: [Contact Heating demonstration] / Foundry Research Institute // YouTube. - Access mode: https://www.youtube.com/watch?v=2c-Wj6YrmNk - The title from the screen. - Date of publication: 21.11.2017. - Revision Date: 11.12.2019.

8. Wettability tests of liquid AM60 alloy on steel-1H18N8T substrate (capillary purification procedure) [Electronic resource]: [Capillary Purification demonstration ] / Foundry Research Institute // YouTube. - Access mode: https://www.youtube.com/watch?v=W-7fXYTquD0 - The title from the screen. - Date of publication: 6.09.2017. - Revision Date: 11.12.2019.

9. Lytvyn M. Software for determination of surface tension with sessile drop method // TASK QUARTERLY vol. 21, No 1, 2017, pp. $65-76$

10. Kiselev M.G. Determination of the wetting angle on flat surfaces / M.G. Kiselev, V.V. Savich, T.P. Pavich // Bulletin of the Belarusian National Technical University. 2006. № 1. C. 38-41.

11. Marchuk. I.V. Determination of surface tension and contact angle of wetting by the surface shape of axisymmetric bubbles and drops / I.V. Marchuk, V.V. Cheverda, P.A. Strizhak, O.A. Kabov // Thermophysics and Aeromechanics, 2015, Volume 22, No. 3. S.311-317

12. Del Río O.I., Neumann A.W. Axisymmetric drop shape analysis: computational methods for the measurement of interfacial properties from the shape and dimensions of pendant and sessile drops // J. of Colloid and Interface Sci. 1997. Vol. 196, No. 2. P. $136-147$.

13. Zholob S.A., Makievski A.V., Miller R., Fainerman V.B. Optimisation of calculation methods for determination of surface tensions by drop profile analysis tensiometry // Advances in Colloid and Interface Science. 2007. № 134, 135. P. $322-329$. 